\title{
DRONE UAV PEMADAM KEBAKARAN HUTAN OTOMATIS
}

\author{
(DRONE UAV AUTOMATIC FOREST FIRE EXTINGUISHER)
}

\author{
Yusuf Arqam Nurkarim ${ }^{1)}$, Assllia Johar Latipah ${ }^{2)}$, dan Sayekti Harits Suryawan ${ }^{3)}$ \\ ${ }^{1,2,3)}$ Universitas Muhammadiyah Kalimantan Timur \\ Samarinda \\ e-mail: $17111024410021 @ u m k t . a c . i d^{1)}, \underline{a j 1722 @ u m k t . a c . i d^{2)}}, \underline{\text { shs500@umkt.ac.id }{ }^{3)}}$
}

\begin{abstract}
ABSTRAK
Tingginya angka luas lahan yang rusak akibat kebakaran hutan di Indonesia menjadi masalah yang selalu kerap kita hadapi. Penangan yang sulit membuat susahnya proses pemadaman secara cepat sehingga membuat kebakaran hutan menjadi luas. Salah satu salusi untuk menanggulangi hal tersebut adalah membuat robot Drone UAV Pemadam Kebaran Hutan Otomatis agar dapat dengan cepat melakukan pemadaman sehingga titik api dapat ditanggulangi sebelum semakin meluas. Drone UAv sendiri merupakan salah satu wahana terbang multicopter yang dapat dikendalikan secara manual dan otomatis sehingga lebih mudah menjangkau titik yang tidak dapat dijangkau oleh manusia. Dengan menanamkan sensor pendeteksi api alat ini mampu mengenali titik api berdasarkan gelombang infrared yang dipancarkan api tersebut. Mikrokontroler Arduino membuat drone UAV dapat terbang otomatis menuju titik kebakaran berdasarkan sinyal yang dikirimkan oleh sensor pendeteksi api. Menggunakan GPS sebagai pemandu arah sehingga akurasi arah terbang drone lebih akurat dan dengan cepat dapat melepaskan alat pemadam kebakaran untuk memadamkan api sebelum api tersebut membesar.
\end{abstract}

Kata Kunci: Kebakaran, Hutan, Drone, Sensor, Arduino.

\begin{abstract}
The high number of land areas damaged by forest fires in Indonesia is a problem that we often face. Handling that is difficult makes it difficult to extinguish quickly so that the forest fires become widespread. One solution to overcome this is to make an Automatic Forest Fire Fighting UAV Drone Robot so that it can quickly extinguish so that hotspots can be overcome before they become more widespread. The UAV drone itself is one of the multicopter flying vehicles that can be controlled manually and automatically, making it easier to reach points that cannot be reached by humans. By implanting a fire sensor, this tool is able to recognize fire points based on the infrared waves emitted by the fire. The Arduino microcontroller allows UAV drones to fly automatically to the point of fire based on the signal sent by the fire sensor. Using GPS as a directional guide so that the accuracy of the drone's flying direction is more accurate and can quickly release a fire extinguisher to extinguish the fire before it gets bigger.
\end{abstract}

Keywords: Fires, Jungle, Drone, Sensor, Arduino.

\section{PENDAHULUAN}

$\mathrm{K}$ ondisi hutan Indonesia saat ini dapat dikatakan tersaji cukup apik sepanjang 2019. Beragam kasus, problematika, dan peristiwa telah terjadi mulaidari kontroversi ekspansi sawit di kawasan hutan yang kian masif, perhutanan sosial, pasar karbon, kemudian hal yang paling mengelus dada tidak lain adalah kasus kebakaran hutan dan lahan (karhutla), serta banyak permasalahan lainnya.
Namun pada tahun 2019 tercatat banyaknya bencana kebakaran hutan yang menimpa Indonesia. Proses pemadaman yang sangat sulit dilakukan mengingat luas hutan di Indonesia dan kontur geografis yang sebagian besar merupakan daera pegunungan merupakan salah satu hambatan dalam proses pemadaman kebakaran hutan. Sehingga menyusahkan para pemadam baik yang menggunakan semprotan air jarak dekat ataupun pesawa tpemadam 
Menurut Madani, bencana karhutla tahu 2019, titik panas (hot spot) sebanyak 13.029 di Agustus 2019, kemudian meningkat signifikan pada September yakni sebanyak 50.267 titik panas, dan kembali mereda di Oktober menjadi 19169. Jika dilakukan deliniasi melalui peta terhadap temuan tersebut, maka pada Agustus tersebut terdapat seluas 1.420 .254 ha terbakar, 5.146.046 ha pada September, dan 5.222.911 ha pada Oktober. Penyebab luasan lahan terbakar lebih besar pada Oktober 2019, karena titik panas di Oktober tersebut tersebar dengan rentang yang cukup jauh sehingga mencakup kawasan persebaran yang lebih besar [1].

Pemadam kebakaran umumnya memiliki tiga tujuan - melindungi dan menyelamatkan jiwa, memadamkan api, dan melindungi / menyelamatkan sifat fisik. Sampai saat ini, alat pemadam kebakaran di Indonesia relatif berteknologi rendah - truk, tangga, dan selang. Oleh karena itu diperlukan teknologi yang dapat mendeteksi kebakaran hutan dini, sehingga bisa dengan cepat dipadamkan dan tidak meluas.

Penggunaan robot drone dan menara sensor yang dapat mendeteksi apai dalam jarak tertentu merupakan salah satu metode yang tepat untuk memecahkan masalah kebakaran hutan di Indonesia. Pemadam kebakaran di Indonesia belum ada yang menggunakan drone, tetapi diluar negeri seperti Amerika, banyak departemen pemadam kebakaran sudah menggunakan drone seperti Model DJI Zenmuse XT dan Z30, serta Matrice 210 dan Inspire 1 v2.0 adalah semua model populer dengan pemadam kebakaran untuk melakukan proses pemadaman yang cepat hingga ke titk yang sulit dan berbahaya untuk dijangkau manusia [2].

Ditambah dengan menara sensor yangdapat mendeteksi api dan mampu untuk membedakan panas api dan panas mahluk hidup. Sehingga robot drone dapat dengan mudah mendeteksi titik api.

Dengan tidak menggunakan manusia dalam proses pemadamannya, serta menara sensor yang dapat membedakan antara panas api dan panas mahluk hidup dapat dengan mudah menghentikan kebakaran hutan dengan mengi- rim drone yang dibekali alat pemadam kebakaran dan memedamakan api sebelum api membesar.

\section{II.STUDI PUSTAKA}

Pembahasan pada bab ini adalah tentang teori penunjang penelitan robot pemadam kebakaran hutan berbasi dorne UAV menggunkaan sensor photodioda dan GPS.

\section{Drone UAV}

Drone adalah sebuat pesawat tanpa awak yang dapat dikendalikan dari jarak jauh menggunakan remote control yang dapat digunakan untuk membawa muatan [3].

Drone yang memiliki sistem kendali otomatis tanpa operator disebut dengan UAV(Unmanned Aerial Vehicle). UAV dapat dikendalikan dengan cara manual ataupun otomatis dengan mengolah data sensor sehingga dapat digunakan sesuai dengan keingginan pengguna.

\section{Sensor Pendeteksi Api}

Sensor cahaya adalah komponen yang elktronika yanfg berfungsi untuk mengubah suatu besaran optik (cahaya) menjadi besaran elektrik. Ada dua jenis sensor berdasarkan perubahan elektrik yang dihasilka, foto voltaik dan foto konduktif. [4].

\section{GPS}

GPS (Global Positioning System) adalah sistem satelit navigasi dan penentuan posisi, dimiliki dan dikelola oleh Amerika Serikat. Sistem ini didesain untuk memberikan posisi dan kecepatan tiga-dimensi serta informasi mengenai waktu, secara kontinyu di seluruh dunia tanpa bergantung waktu dan cuaca, bagi banyak orang secara simultan. Saat ini GPS sudah banyak digunakan orang di seluruh dunia dalam berbagai bidang aplikasi yang menuntut informasi tentang posisi, kecepatan, percepatan ataupun waktu yang teliti. GPS dapat memberikan informasi posisi dengan ketelitian bervariasi dari beberapa millimeter (orde nol) sampai dengan puluhan meter. Hingga saat ini GPS merupakan sistem satelit navigasi yang paling populer dan paling banyak diaplikasikan di dunia, baik di da- 
rat, laut, udara, maupun angkasa. Disamping aplikasi- aplikasi militer, bidang- bidang aplikasi GPS yang cukup banyak saat ini antara lain meliputi survei pemetaan, geodinamika, geodesi, geologi, geofisik, transportasi dan navigasi, pemantauan deformasi, pertanian, kehutanan, dan bahkan juga bidang olahraga dan rekreasi[5].

\section{Micro Controller}

Mikrokontroler adalah chip berupa IC (Integrated Circuit) yang dapat menerima sinya input, melakukan pengelolaan dan memberikan sinyal output dengan program yang telah diisikan kedalamnya. Sinyal input berasal dari sensor yang memberikan sinyal yang dibutuhkan dan mengelolanya menjadi perintah output. Pada dasarnya mikrokontroler memiliki kecepatan prosesor yang lebih rendah dibandingkan PC [6].

\section{METODE PENELITIAN}

Metode yang digunakan dalam penelitian ini menggunakan metode Systematic Literature Reviews dengan menelaah 12 jurnal terkait drone UAV dan sensor pendeteksi api, sebelum akhirnya dilakukan implementasi secara bertahap.

\section{HASIL DAN PEMBAHASAN}

Dalam penelitian ini semua hal yang dibutuhkan dalam pembangunan Drone UAV Pemadam Kebakaran Otomatis Menggunakan Sensor Photodioda dan Arduino akan dibahas berdasarkan studi literatur yang digunakan.

\section{A. Drone}

\section{1) Drone UAV}

Unmanned Aerial Vehicle (UAV) atau kendaraan udara tanpa awak adalah salah satu teknologi yang sedang mengalami perkembangan yang pesat dan memiliki potensi yang sangat besar, baik untuk keperluan militer maupun kepentingan sipil. Contoh aplikasi yang dapat diimplementasikan pada UAV adalah untuk kebutuhan survey, patroli, deteksi tambang mineral, riset, fotografi, dan keperluan lain. Kelebihan dari UAV adalah dapat digunakan pada misi-misi berbahaya tanpa membahayakan pilot / manusia.

UAV awal dibuat kebanyakan untuk kepentingan militer. Seiring berkembang teknologi dan banyak penelitian yang berkaitan dengan UAV, sekarang UAV memiliki fungsi yang berbeda-beda. Salah satu adalah
Transportasi UAV yang dapat mengangkut barang pada bagian pesawat, namun untuk UAV jenis helikopter dapat mengangkut barang diluar badan pesawat. Beban yang diberikan pada UAV ini biasa beban yang tergolong ringan dan membutuhkan kecepatan pengiriman dan resiko pengiriman yang tinggi. Pesawat tanpa awak dapat digunakan pada daerah berbahaya yang apabila dilakukan dengan pesawat berawak akan membahayakan keselamatan awak pesawat tersebut. Daerah yang berbahaya tersebut daerah pusat badai, ketinggian yang berbahaya, daerah rawan perang, dsb. Beberapa UAV dilengkapi dengan senjata yang digunakan pada kawasan perang, seperti Predator RQ-1 yang telah dapat melakukan serangan ke target-target di darat, bahkan Predator RQ-1 juga dapat melakukan perang antar pesawat di udara.

Kemampuan pesawat UAV semacam ini sangat menguntungkan bagi negara-negara maju, karena resiko penggunaan pilot sebagai sandera atau tawanan perang apabila tertangkap dapat dihilangkan [7].

\section{2) Quadcopter}

Quadcopter merupakan pesawat tanpa awak yang memiliki empat buah motor dan balingbaling di tiap ujung- ujung kerangka utama. Bagian tengah digunakan untuk peletakkan, sistem kontrol, sensor dari quadcopter, dan sumber daya (baterai). Sistem kontrol digunakan untuk mengatur kecepatan tiap-tiap motor sesuai dengan gerakan yang diinginkan seperti bermanuver maju, mundur, kiri, kanan, atas, bawah, dan juga berotasi.

Tiap motor pada quadcopter bertanggung jawab dalam pergerakan dan energi putarannya, begitu juga dengan gaya tarikan yang berlawanan dari arah terbang quadcopter. Baling- baling pada quadcopter tidak sepenuhnya sama dalam pergerakannya. Pada prosesnya, baling- baling ini dibagi menjadi 2 pasang, 2 baling- baling pendorong dan 2 baling- baling penarik yang bergerak dalam putaran yang berlawanan. Sebagai konsekuensinya, hasil putaran menjadi penyeimbang jika semua baling- baling berputar dengan kecepatan sama, sehingga membuat kendaraan terbang dapat terbang stabil di satu tempat [8].

\section{B. Sensor Pendeteksi Api \\ 1) Sensor UVtrone Flame Detector \\ Hamamatsu UVTron Flame Detector dan rangkaian driver-nya dapat mendeteksi api dari}


lilin dalam jarak 5 meter. Sensor ini digunakan sebagai alat untuk mendeteksi sumber api yang beroperasi pada panjang spectral $185 \mathrm{~nm}$ hingga $160 \mathrm{~nm}$.

Tabung UVTron bekerja ketika pada katoda diberikan sinyal ultraviolet, fotoelektron akan dipancarkan dari katoda oleh efek fotoelektrik dan dipercepat ke anoda menggunakan medan listrik. Ketika tegangan diberikan, medan magnet meningkat, medan listrik semakin besar dan Energi kinetik elektron menjadi besar untuk mengionisasi molekul gas di 12 tabung untuk bertubrukan. Elektron yang dibangkitkan oleh ionisasi dipercepat yang membuat elektron mengionisasi molekul lainnya sebelum mencapai anoda. Ion positif yang dipercepat ke katoda dan bertubrukan menyebabkan elektron sekunder lainnya, kejadian ini menyebabkan arus yang cukup besar diantara elektroda dan terjadi pembuangan muatan[9].

\section{2) Sensor Infrared}

Sensor Infrared pada modul Flame Sensor dapat membaca panjang gelombang dengan range panjang gelombangnya berkisar antara $760 \mathrm{~nm}$ $1100 \mathrm{~nm}$. Infra merah merupakan warna dari cahaya tampak dengan panjang gelombang sekitar $700 \mathrm{~nm}$ sampai $1 \mathrm{~mm}$. Sedangkan cahaya ultraviolet memancarkan cahaya dengan panjang gelombang sekitar $300 \mathrm{~nm}-400 \mathrm{~nm}$. Sensor ini bisa mendeteksi cahaya tampak, sinar infra merah dan sinar ultraviolet. Sensor ini memiliki karakteristik tegangan keluaran tinggi saat tidak ada api dan keluaran rendah saat ada api dengan panjang gelombang rendah. Sensor ini dapat mendeteksi gelombang infra merah yang di pancarkan oleh api, sehingga sensor tersebut dapat digunakan sebagai pendeteksi kebakaran. Lampu indikator LED mati atau logika Low (0) jika tidak mendeteksi api. sedangkan jika sensor mendeteksi api, lampu indikator LED menyala atau logika High (1) [10].

\section{3) Sensor Photodioda}

Photodioda adalah suatu jenis dioda yang resistansinya akan berubah-ubah apabila terkena sinar cahaya. Resistansi dari photodioda dipengaruhi oleh intensitas cahaya yang diterimanya, semakin banyak cahaya yang diterima maka semakin kecil resistansi dari photodioda dan begitu pula sebaliknya jika semakin sedikit intensitas cahaya yang diterima oleh sensor photodioda maka semakin besar nilai resistansinya. Sensor photodioda sama seperti sensor LDR, mengubah besaran cahaya yang diterima sensor menjadi perubahan konduktansi (kemampuan suatu benda menghantarkan arus listrik dari suatu bahan).

Pada penelitian sebelumnya telah digunakan sensor photodioda sebanyak 5 buah pada robot pemadam api berkaki dengan tujuan agar dapat mendeteksi api lilin dengan sudut pandang $180^{\circ}$. Pada penelitian ini digunakan sensor photodioda sejumlah 8 buah dan diletakkan menyebar agar sensor dapat mendeteksi api secara maksimal. Sistem deteksi api ini bekerja dengan logika OR, dimana jika salah satu sensor dari ke delapan buah sensor photodioda mendeteksi adanya api maka bazzer akan berbunyi. Gambar 1 merupakan skema rangakaian dari sensor api menggunakan photodioda.

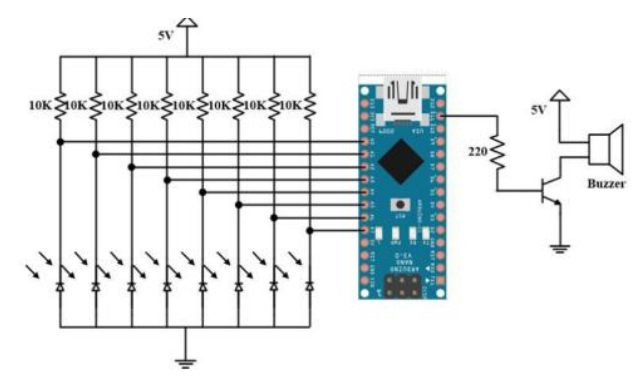

Gambar 1. Skema rangkaian

Pada perancangan rangkaian menggunakan resistor $10 \mathrm{~K} \Omega$ berdasarkan pada perhitungan bahwa photodioda tersebut berkerja dengan tegangan sebesar $2 \mathrm{~V}$ dengan arus sebesar 0,33 $\mathrm{mA}[11]$.

\section{Arduino Nano}

Adruino adalah papan elektronik bersifat open source. Didalamnya terdapat komponen utama, yaitu chip mikrokontroler Atmega328 dari jenis AVR dari perusahan Atmel. Mikrokontroler tersebut dapat diprogram menggunakan komputer sehingga dapan menerima input, memproses, dan memberikan output yang diinginkan [12].

\section{Navigasi}

Navigasi dalam penelitian ini menggunakan GPS yang berfungsi untuk menyediakan informasi kordinat posisi, kecepatan, waktu tempuh, ketinggian, dan informasi tambahan yang akan 
diinput kedalam program berbasis mikrokontorller Arduino.

Pada mode manual, mikrokontroler Arduino akan melewatkan sinyal PWM dari nano arduino dan merekontruksi pulsa menggunakan inputoutput timer. Ketika dalam mode otomatis, kontroler akan mengolah data sesnsor dan kestabilan drone di udara. Dibuthkan hardware yang melakukan sinkronisasi untuk mendapatkan data pergerakan akuator drone terhadapa perubahan sinyal PWM. Setelah itu software akan mengolah data untuk mengkoneksikan komponen elektronik agar sistem dapat berjalan dengan baik yang meliputi penentuan sudut pitch/roll dan penerimaan input PWM serta pengiriman output PWM [13].

\section{KESIMPULAN}

Berdasarkan pembahasan studi literatur diatas dapat diambil kesimpulan dengan menggunakan drone UAV quadcopter membuat perangkat dapat mengangkut beban berat sehingg dapat dengan mudah membawa alat pemadam kebakaran menuju titik api.

Selain itu sensor yang tepat untuk digunakan sebagai pendeteksi api pada drone UAV adalah photodioda. Photodioda mampu mendeteksi cahaya infrared yang dipancarkan oleh api dalam luas jangakuan $180^{\circ}$. Selain itu sensor api photodioda juga mampu menembus objek yang cukup tebal sehingga niali akurasi pendeteksian api akan bertambah tinggi.

Menggunakan Adruino dan mikrokontroler sebagai kendali untuk menerbangkan drone UAV menuju titik api sehingga dapat berkerja secara otomatis setelaah menerima informasi dari sensor pendeteksi api.

Dan untuk sistem navigasi yang idurnakan adalah Global Positioning System (GPS). Keakuratan GPS dalam menentukan kordinat, ketinggian , dan kemiringan membuat GPS menjadi sistem navigasi yang unggul sehingga mengurangi kesalahan pemetaan tujuan yang dapat mempengaruhi akurasi tingkat kinerja Drone UAV Pemadam Kebakaran Otomatis.

Untuk implementasi pembuatan prototype akan segera dilaksanakan setelah dilakukan proses perhitungan yang lebih detail dan mendalam sehingga dapat diperoleh data akurat sebelum uimplementasi.

\section{DAFTAR PUSTAKA}

[1] Ferdian. Delly. (2019, Desember). Catatan Hutan Indonesia 2019 [Online]. Avaiable : https://www.madaniberkelanjutan.id/

[2] Fauzi, Ahmad Maulana, "Pemanfaatan Pesawat Nirawak Pada Pemadam Kebakaran Hutan". STIMIK Sumedang. Sumeang, 2019.

[3] Suroso, Indreswari, "Analisis Pemetaan Daerah Rawan Banjir dan Longsor Dengan Drone Type Mutlicopter Di Girimulyo, Kabupaten Kulonprogo", Teknika STTKD: Jurnal Teknik, elektronik, Engine vol. 5, no. 1, Juli 2018

[4] Erni Setyaningsih, Dhidik Prastiyanto , dan Suryono,"Penggunaan Sensor Photodioda sebagai Sistem Deteksi Api pada Wahana Terbang Vertical Take-Off Landing (VTOL)", Jurnal Teknik Elektro Vol. 9 No. 2 , Juli-Desember 2017.

[5] Herlambang Sigit Pramono, "Pembacaan Posisi Koordinat Dengan GPS Sebagai Pengendali Palang Pintu Rel Kereta Api Secara Otomatis Untuk Penambahan Aplikasi Modul Praktik Mikrokontroler", Jurnal Pendidikan Teknologi dan Kejuruan, Volume 20, Nomor 2, Oktober 2011.

[6] Zulkarnaen, "Smart SprayerDisinsfektan BerbasisMikrokontrolerAtmegA328”, Jurnal TEKNIMEDIA-Volume 1, Nomor 1, Mei 2020.

[7] Adkha Yulianandha Mabrur. Analisis Pemanfaatan Opensource Dronedeploy Dalam Proses Mozaik Foto Udara (Uav). Teknik Sipil dan Perencanaan ITN. Malang. 2020.

[8] Hardy Samuel Saroinsong, Vecky C. Poekoel, Pinrolinvic D.K Manembu, "Rancang Bangun Wahana Pesawat Tanpa Awak (Fixed Wing) Berbasis Ardupilot", Jurnal Teknik Elektro dan Komputer vol. 7 no. 1, 2018.

[9] Harnan Sholichul Amri. Sensor Uvtron Sebagai Pendeteksi Api Pada Robot Pemadam Api Berbasis Mikrokontroler Atmega8535. Ilmu Komputer USM. Surakarta 2010.

[10] Erni Setyaningsih , Dhidik Prastiyanto , dan Suryono,"Penggunaan Sensor Photodioda sebagai Sistem Deteksi Api pada Wahana Terbang Vertical Take-Off Landing (VTOL)", Jurnal Teknik Elektro Vol. 9 No. 2, Juli-Desember 2017.

[11] Rahmad Hidayat dan Ronny Mardiyanto, "Pengembangan Sistem Navigasi Otomatis Pada UAV (Unmanned Aerial Vehicle) dengan GPS(Global Positioning System) Waypoint", Jurnal Teknik ITS Vol.5, No.2,2016. 
TEKNIMEDIA - Volume 01, Nomor 2, Desember $2020: 1$ - 6

\section{Referensi tambahan :}

[12] Rahardhita Widyatra Sudibyo ,Achmad Subhan Khalilullah,ST ,Haniah Mahmudah,ST,MTD, "Pemetaan Posisi dan Sistem Navigasi Mobile Robot Dalam Ruang Menggunakan Sensor Perpindahan Jenis Optical Laser", Politeknik Elektronika Surabaya. Surabaya. 2019

[13] Suhardi, "Pemupukan Tanaman Otomatis Menggunakan Sensor Ultrasonik Dan Cahaya Berbasis Arduino Uno R3”, JISTech, 5(1), 49-61, Januari-Juni 2020. 